\title{
Left Subcostal Vein
}

National Cancer Institute

\section{Source}

National Cancer Institute. Left Subcostal Vein. NCI Thesaurus. Code C53125.

A vein that extends along the bottom of the twelfth rib on the left side of the body. 